\title{
Peran Orang Tua dan Sumber Informasi dalam Pendidikan Seks dengan Perilaku Seksual Remaja pada Masa Pubertas di SMAN 1 Turi
}

\author{
Sujarwati ${ }^{1}$, Anafrin Yugistyowati $^{2}$, Kayat Haryani ${ }^{3}$ \\ 1,2,3 Sekolah Tinggi IImu Kesehatan Alma Ata Yogyakarta \\ Jalan Ringroad Barat Daya No 1 Tamantirto, Kasihan, Bantul, Yogyakarta
}

\begin{abstract}
Abstrak
Remaja adalah masa transisi atau peralihan dari masa kanak-kanak menuju masa dewasa. Berdasarkan hasil studi pendahuluan dilihat dari grafik gunung es menunjukkan dari 268 siswa sekitar 66 (60\%) siswa laki-laki menjawab pernah melakukan onani dan 5 (1,75\%) siswa yang melakukan konseling menjawab pernah melakukan hubungan seksual dan pada tahun ajaran 2012/2013 terdapat 1 (0,35\%) siswa yang hamil diluar nikah. Tujuan penelitian ini untuk mengetahui hubungan peran orang tua dan sumber informasi dalam pendidikan seks dengan perilaku seksual remaja pada masa pubertas di SMAN 1 Turi. Jenis penelitian ini adalah penelitian induktif dengan menggunakan rancangan Cross Sectional. Sampel penelitian adalah remaja usia 16-19 tahun. Pengambilan sampel menggunakan teknik purposive sampling dengan jumlah 73 responden. Untuk menggambarkan hubungan antara variabel penelitian dengan menggunakan uji Regresi Korelasi Ganda dan Parsial. Hasil penelitian Analisis univariat dari 73 responden peran orang tua baik 50 (68,5\%) orang, sumber informasi banyak 38 (52,1\%) orang dan perilaku seksual remaja baik 53 (72,6\%) orang. Analisis multivariat menunjukkan ada hubungan peran orang tua dan sumber informasi dengan perilaku seksual remaja pada masa pubertas di SMAN 1 Turi dengan nilai $p=0,000(p<0,05)$. Kesimpulan penelitian terdapat hubungan peran orang tua dan sumber informasi dalam pendidikan seks dengan perilaku seksual remaja pada masa pubertas di SMAN 1 Turi.
\end{abstract}

Kata Kunci: peran orang tua, perilaku seksual remaja, sumber informasi

\section{Role of Parents and Information Resources in Sex Education with Sexual Behavior of Adolescents Period in Puberty at SMAN 1 Turi}

\begin{abstract}
Adolescent is transition period or transition from childhood to adulthood. Based on the baseline study, showed that from 268 students about 66 (60\%) male students said that they ever doing masturbation and 5 (1.75\%) students who take counseling had ever sexual intercourse and in the academic year 2012/2013 there was 1 (0.35\%) student was pregnant before marriage. The purpose of this research was to observe role of parents and information resources relationship in sex education with sexual behavior adolescents in puberty at SMAN 1 Turi. Study design was inductive with cross sectional. The samples were adolescents aged 16-19 years. The sampling technique was done by purposive sampling resulted on 73 respondents. The analysis used Multiple Regression and Partial Correlation Test. The results showed that 50 (68.5\%) students with role of parents was good, information resources 38 (52.1\%) students and sexual behavior of adolescent 53 (72.6\%) students was good. Multivariate analysis showed that there was the relationship between role of parent and information resources with sexual behavior period in puberty at SMAN 1 Turi with $p=0.000(p<0.05)$. In conclusion, there was relationship between role of parents and information resources in sex education with sexual behavior of adolescent in puberty at SMAN 1 Turi.
\end{abstract}

Keywords: adolescent sexual behavior, information resources, parent role

Info Artikel:

Artikel dikirim pada 5 September 2014

Artikel diterima pada 5 September 2014 


\section{PENDAHULUAN}

Data demografi berdasarkan Badan Pusat Statistik menunjukkan bahwa jumlah penduduk Indonesia pada tahun 2010 yaitu 237,6 juta jiwa dan 63,4 juta jiwa diantaranya adalah remaja usia 10-24 tahun(1). Berdasarkan Badan Koordinasi Keluarga Berencana Nasional jumlah remaja usia 10-24 tahun diantaranya remaja laki-laki sebanyak 30,1 juta jiwa $(50,70 \%)$ dan remaja putri sebanyak 31,2 juta jiwa $(49,30 \%)$. Penduduk remaja usia 10-24 tahun di Provinsi Daerah Istimewa Yogyakarta tahun 2010 sebanyak 64 juta jiwa $(27,6 \%)$ dari jumlah penduduk 237,6 juta jiwa(2).

Remaja (adolescence) adalah masa transisi atau peralihan dari masa kanak-kanak menuju masa dewasa yang ditandai dengan adanya perubahan aspek-aspek fisik, psikis, dan psikososial(3).

Perkembangan media teknologi dan informasi dapat memberi pengaruh besar pada perkembangan anak. Tidak diragukan lagi bahwa sumber media informasi dapat memperluas pengetahuan anak tentang dunia tempat mereka hidup. Namun, terdapat peningkatan kekhawatiran mengenai berbagai pengaruh media informasi pada perkembangan anak. Anak-anak masa kini cenderung memilih media informasi dan figur sebagai model peran ideal mereka, sedangkan di masa lalu mayoritas anak memilih orang tua atau wali orang tua mereka sebagai orang yang paling mereka contoh(4).

Media informasi memberi beberapa pengaruh terhadap perilaku dan hubungan sosial anak remaja. Perilaku dan hubungan seksual anak remaja seperti gaya berpacaran sangat berbeda dengan remaja dahulu. Remaja saat ini lebih terbuka dan bebas untuk melakukan apapun demi keseriusan kepada pasangannya. Semua aktivitas itu yang akhirnya mempengaruhi niat untuk melakukan seks lebih jauh seperti berciuman sampai melakukan hubungan seksual dengan pasangannya(5).

Berdasarkan survei yang dilakukan oleh Riset Kesehatan Dasar dari keseluruhan remaja usia 10-24 tahun dari jumlah sampel 63.048 orang yang berstatus belum menikah adalah $86,7 \%$. Pada kelompok tersebut, remaja laki-laki sebanyak 31.372 orang $(3,0 \%)$ dan perempuan sebanyak 31.676 orang $(1,1 \%)$ menjawab pernah berhubungan seksual. Data RISKESDAS menunjukkan bahwa umur pertama berhubungan seksual sudah terjadi pada usia yang sangat muda yaitu 8 tahun. Terdapat 31.676 orang $(0,5 \%)$ pada remaja perempuan dan 31.372 orang $(0,1 \%)$ pada remaja laki-laki telah melakukan hubungan seksual pertama kali saat usia 8 tahun(6).

Hal-hal yang menyebabkan terjadinya perilaku seksual pada remaja adalah pengawasan dan perhatian orang tua yang longgar, pola pergaulan yang bebas, lingkungan yang bebas, semakin banyaknya halhal yang memberikan rangsangan seksual yang sangat mudah dijumpai dan fasilitas seperti televisi, handphone, komputer dan media massa yang seringkali diberikan oleh keluarga tanpa menyadari efek dari penggunaannya. Efek dari penggunaan fasilitas tersebut dapat menyebabkan remaja ingin meniru tokoh yang diidolakan seperti perilaku remaja yang ingin pacaran. Masa pacaran telah diartikan sebagai masa untuk belajar melakukan aktivitas seksual dengan lawan jenis, mulai dari ciuman, saling masturbasi, seks oral, bahkan sampai hubungan seksual(5).

Penelitian Suprapti menunjukkan bahwa ada hubungan antara peran orang tua dengan pengetahuan remaja tentang pubertas serta ada hubungan antara tingkat pendidikan orang tua dengan pubertas remaja di SMP Negeri 2 Andong Boyolali. Hasil penelitian menunjukkan bahwa tingkat pendidikan orang tua mempunyai kontribusi paling besar terhadap pengetahuan remaja tentang pubertas(7).

Berdasarkan hasil studi pendahuluan di SMAN 1 Turi pada tanggal 2 Desember 2013, melalui wawancara dengan guru Bimbingan Konseling (BK) menunjukkan bahwa hasil dari bimbingan konseling siswa-siswi yang dilihat dari grafik gunung es dari 286 siswa sekitar 66 siswa laki-laki $(60 \%)$ melakukan onani dan 5 siswa $(1,75 \%)$ melakukan konseling diketahui pernah melakukan hubungan seksual. Pada tahun pelajaran 2012/2013 lalu terdapat 1 siswa $(0,35 \%)$ yang hamil di luar nikah.

Berdasarkan hasil wawancara dengan 5 orang tua siswa bahwa mereka kurang optimal dalam memberikan informasi dan pendidikan seks kepada anaknya. Orang tua lebih mengutamakan memberikan bekal agama dikarenakan anak tidak akan melakukan hal yang menyimpang. Orang tua percaya dengan sekolah untuk memberikan informasi dan pendidikan seks kepada anaknya karena lebih terarah dari pada yang didapatkan dari keluarga.

Tujuan penelitian untuk mengetahui hubungan antara peran orang tua dan sumber informasi dalam pendidikan seks dengan perilaku seksual remaja pada masa pubertas.

\section{BAHAN DAN METODE}

Jenis penelitian ini adalah induktif dengan rancangan cross sectional. Penelitian ini dilaksanakan di SMANegeri 1 Turi pada tanggal 3 Juni 2014. Populasi dalam penelitian ini adalah siswa-siswi SMA Negeri 1 Turi dengan jumlah 286 siswa. Teknik pengambilan sampel menggunakan purposive sampling. Jumlah sampel dalam penelitian ini menurut tabel Krejcie adalah 73 siswa. Variabel bebas pada penelitian ini yaitu peran 
orang tua dan sumber informasi dalam pendidikan seks. Variabel terikat pada penelitian ini yaitu perilaku seksual remaja pada masa pubertas. Instrumen yang digunakan dalam penelitian ini adalah kuesioner.

\section{HASIL DAN BAHASAN}

\section{Karakteristik Orang Tua}

Berdasarkan Tabel 1 karakteristik orang tua berdasarkan pekerjaan dan penghasilan didapatkan sebagian besar orang tua responden bekerja menjadi karyawan swasta sebesar 39,7\% (29 orang) dan penghasilan sebagian besar Rp 1.000.000Rp 3.000.000 sebesar $72,6 \%$ (53 orang). Tingkat kemampuan seorang untuk memenuhi kebutuhan hidup tergantung dengan hasil pendapatan(8).

Tabel 1. Distribusi Frekuensi Karakteristik Orang Tua di SMAN 1 Turi

\begin{tabular}{lcc}
\hline \multicolumn{1}{c}{ Karakterisrik } & f & \% \\
\hline Pekerjaan & 19 & 26,0 \\
Tani & 29 & 39,7 \\
Karyawan Swasta & 1 & 1,4 \\
Buruh & 18 & 24,7 \\
PNS & 6 & 8,2 \\
Wiraswasta & & \\
Penghasilan & 12 & 16,4 \\
< Rp 1.000.000 & 53 & 72,6 \\
Rp 1.000.000- Rp 3.000.000 & 8 & 11,0 \\
> Rp 3.000.000 & 73 & 100,0 \\
\multicolumn{2}{c}{ Total }
\end{tabular}

Sumber: Data Primer 2014

\section{Karakteristik Responden Penelitian}

Berdasarkan Tabel 2 karakteristik responden berdasarkan jenis kelamin, umur dan kelas. Hasil penelitian didapatkan responden sebagian besar berjenis kelamin laki-laki sebesar 68,5\%, (50 orang), sebagian besar berumur 17 tahun sebesar $53,4 \%$ (39 orang) dan sebagian besar kelas XI IPS sebesar $31,5 \%$ (23 orang).

Pada masa ini remaja sudah mulai mencoba melakukan onani karena telah seringkali terangsang secara seksual akibat pematangan yang dialami. Rangsangan ini diakibatkan oleh faktor internal yaitu meningkanya kadar testosteron pada laki-laki dan estrogen pada remaja perempuan. Sebagian dari mereka amat menikmati apa yang mereka rasakan, tetapi ternyata sebagian dari mereka justru selama atau sesudah merasakan kenikmatan tersebut kemudian merasa kecewa dan merasa berdosa. Perasaan berdosa ini diakibatkan pemahaman agama yang mereka pahami(9).
Tabel 2. Distribusi Frekuensi Karakteristik Remaja SMAN 1 Turi

\begin{tabular}{lcc}
\hline \multicolumn{1}{c}{ Karakterisrik } & $\mathbf{f}$ & $\mathbf{\%}$ \\
\hline $\begin{array}{c}\text { Jenis Kelamin } \\
\text { Laki-Laki }\end{array}$ & 50 & 68,5 \\
Perempuan & 23 & 31,5 \\
Umur & & \\
16 Tahun & 29 & 39,7 \\
17 Tahhun & 39 & 53,4 \\
18 Tahun & 4 & 5,5 \\
19 Tahun & 1 & 1,4 \\
Kelas & & \\
X1 & 6 & 8,2 \\
X2 & 11 & 15,1 \\
X3 & 8 & 11,0 \\
X4 & 10 & 13,7 \\
XI IPA & 15 & 20,5 \\
XI IPS & 23 & 31,5 \\
Total & 73 & 100,0 \\
\hline
\end{tabular}

Sumber: Data Primer 2014

Tabel 3. Distribusi Frekuensi Berdasarkan Hobi Siswa SMAN 1 Turi

\begin{tabular}{ccc}
\hline Hobi & $\mathbf{f}$ & $\mathbf{\%}$ \\
\hline Volly & 12 & 16,4 \\
Sepak Bola & 35 & 47,9 \\
Pencak Silat & 3 & 4,1 \\
Basket & 8 & 11,0 \\
Badminton & 2 & 2,7 \\
Renang & 11 & 15,1 \\
Lari & 2 & 2,7 \\
Total & 73 & 100,0 \\
\hline
\end{tabular}

Sumber: Data Primer 2014

Berdasarkan Tabel 3 didapatkan distribusi frekuensi karakteristik responden berdasarkan hobi, dimana responden sebagian besar memiliki hobi sepak bola yaitu sebesar 47,9\% (35 orang). Hasil ini sesuai dengan penelitian lain yang hasilnya sebagian besar adalah berjenis kelamin laki-laki, dan memiliki hobi sepak bola. Upaya menurunkan perilaku seksual yang negatif pada remaja dengan melakukan kegiatan seperti menyalurkan hobi, olahraga, main musik dan seni(10).

\section{Analisis Univariat}

Berdasarkan hasil penelitian pada Tabel 4 didapatkan peran orang tua sebagian besar kategori baik sebesar $68,5 \%$ (50 orang), sumber informasi sebagian besar kategori banyak sebesar $52,1 \%$ (38 orang) dan perilaku seksual tergolong baik sebesar $72,6 \%$ (53 orang).

Hasil penelitian ini menggambarkan peran orang tua dalam memberikan pendidikan seks 
Tabel 4. Distribusi Frekuensi Peran Orang Tua, Sumber Informasi dan Perilaku Seksual Siswa SMAN 1 Turi

\begin{tabular}{lcc}
\hline \multicolumn{1}{c}{ Variabel } & f & \% \\
\hline $\begin{array}{l}\text { Peran Orang Tua } \\
\text { Baik }\end{array}$ & 50 & 68,5 \\
$\quad$ Cukup & 23 & 31,5 \\
Sumber Informasi & & \\
$\quad$ Banyak & 38 & 52,1 \\
$\quad$ Cukup & 33 & 45,2 \\
$\quad$ Kurang & 2 & 2,7 \\
Perilaku Seksual & & \\
Baik & 53 & 72,6 \\
Cukup & 20 & 27,4 \\
$\quad$ Total & 73 & 100,0 \\
\hline
\end{tabular}

Sumber: Data Primer 2014

terhadap anak remajanya. Peran orang tua remaja di SMAN 1 Turi Sebagian besar kategori baik karena peran orang tua sudah berkomunikasi baik dengan anak remajanya dan remaja tinggal bersama orang tuanya. Hasil penelitian ini sesuai dengan penelitian Darmasih semakin tinggi peran keluarga terhadap remaja terutama orang tua maka perilaku seks pra nikah remaja semakin baik(11).

Menurut Soetjiningsih, media informasi tidak dapat ditinggalkan untuk ikut serta dalam menyampaikan informasi penting kepada masyarakat umumnya dan remaja. Media massa sangat efektif untuk menyampaikan informasi, serta mempromosikan halhal yang spesifik seperti memberikan informasi kepada remaja tentang perilaku seksual yang sehat dan usia menikah yang dianggap cukup(9). Hasil penelitian ini mengetahui sumber informasi yang positif dari berbagai media informasi (televisi, internet, handphone, radio, majalah, koran, poster, brosur/pamflet, novel, komik, orang tua, teman) yang didapatkan remaja di SMAN 1 Turi. Hasil penelitian ini tidak sesuai dengan penelitian Darmasih yang menunjukan semakin sedikit sumber informasi yang didapatkan remaja maka semakin baik perilaku seks pranikah remaja(11).

Menurut Sarwono perilaku seksual adalah segala tingkah laku yang didorong oleh hasrat seksual, baik dengan lawan jenisnya maupun dengan sesama jenis. Bentuk-bentuk tingkah laku ini bisa bermacam-macam, mulai dari pasangan tertarik sampai tingkah laku berkencan, berciuman, dan bersenggama. Organ seksualnya bisa berupa orang lain dan orang dalam khayalan atau diri sendiri(12). Berdasarkan hasil penelitian pada Tabel 4 didapatkan perilaku seksual tergolong baik sebesar 72,6\% (53 orang). Hasil penelitian ini menggambarkan perilaku seksual yang positif pada remaja di SMAN 1 Turi.

Perilaku seksual remaja di SMAN 1 Turi kategori baik tidak terlepas dari peran orang tua, sumber informasi yang didapat dan keberhasilan sekolah dalam memberikan pendidikan kesehatan reproduksi remaja. Hasil penelitian ini sesuai dengan penelitian Darmasih yang menunjukkan perilaku seks pra nikah remaja baik(11).

\section{Analisis Multivariat}

Berdasarkan hasil penelitian pada Tabel 5 didapatkan nilai $F_{\text {hitung }}=24,098$, sedangkan nilai $F_{\text {tabel }}$ untuk $F$ dengan $\mathrm{db}$ pembilang 2 dan penyebut 70 adalah 3,15 yang berarti $\left(F_{\text {nitung }}>F_{\text {tabel }}\right)$ dan nilai $p=0,000$ $(p<0,05)$. Hasil tersebut menunjukkan terdapat pengaruh peran orang tua dan sumber informasi terhadap perilaku seksual remaja. Kesimpulan, ditolak pada kemaknaan 0,05 atau $p<0,05$.

Tabel 5. Tabel Ringkasan Analisis Regresi antara Variabel Peran Orang Tua dan Sumber Informasi dengan Perilaku Seksual Remaja

\begin{tabular}{|c|c|c|c|c|c|}
\hline Variabel & $\begin{array}{l}\text { Jumlah } \\
\text { Kuadrat }\end{array}$ & $\mathrm{Db}$ & $\begin{array}{c}\text { Rata-Rata } \\
\text { Kuadrat Rk = }\end{array}$ & $\mathbf{F}_{\text {reg }}=\frac{\text { RKreg }}{R \text { RKres }}$ & $p$-value \\
\hline Regresi & 5,921 & 2 & $\mathrm{Rk}=\frac{5,291}{2}=2,960$ & $F_{r e g}=\frac{2,960}{0,123}$ & 0,000 \\
\hline Residu & 8,600 & 70 & $\mathrm{Rk}=\frac{8,600}{70}=0,123$ & $=24,098$ & \\
\hline Total & 14,521 & 72 & & & \\
\hline
\end{tabular}

Sumber: Data Primer 2014

Penelitian ini didukung oleh penelitian Suprapti dan Indrawati yang menyatakan bahwa ada hubungan peran dan tingkat pendidikan orang tua dengan pengetahuan pubertas remaja(7). Dimana pengetahuan memiliki pengaruh terhadap praktik ataupun perilaku(8). Didukung juga oleh Kurni dan Yulian, yang menyatakan bahwa ada hubungan yang bermakna antara komunikasi orang tua dengan perilaku seksual remaja(13). Prevalensi perilaku seksual remaja beresiko tinggi lebih banyak terjadi pada remaja yang memiliki komunikasi buruk dengan orang tua dibandingkan dengan komunikasi yang baik antara orang tua dan remaja. Menurut BKKBN, mengatakan bahwa peran orang tua yaitu sebagai pendidik, sebagai panutan, pendamping, konselor dan komunikator(2). Peran orang tua yang penting adalah menjadi manajer yang efektif yaitu orang tua yang dapat memberikan informasi, membantu menyusun pilihan-pilihan dan memberikan bimbingan kepada anak.

Penelitian yang sama dilakukan Sujalmo, dengan hasil ada hubungan antara peran orang tua dengan kenakalan remaja(14). Disamping komunikasi yang baik dengan anak, orang tua juga perlu mengembangkan kepercayaan anak kepada orang tua sehingga remaja lebih terbuka dan mau bercerita kepada orang tuanya. Harapannya orang tua dapat 
memantau pergaulan anak remajanya, sehingga tidak menyebabkan perilaku yang tidak diharapkan. Semakin tinggi pendidikan orang tua berpengaruh dalam penyampaian pendidikan seks terhadap anak dan lebih terarah dibandingkan dengan pendidikan orang tua yang rendah yang masih menganggap seks merupakan hal yang tabu(15).

Penelitian Hidayana, terdapat hubungan yang sangat bermakna antara pengetahuan, sikap, informasi, lingkungan dan ekonomi dengan perilaku seksual yang beresiko(16). Penelitian ini didukung hasil penelitian Indah, bahwa terdapat pengaruh layanan informasi menggunakan media poster terhadap pencegahan perilaku seksual remaja(17).

\section{SIMPULAN DAN SARAN}

Berdasarkan hasil penelitian yang telah dilakukan dapat disimpulkan bahwa peran orang tua dalam pendidikan kesehatan sebagian besar kategori baik sebesar $68,5 \%$ (50 orang). Sumber informasi dalam pendidikan kesehatan sebagian besar kategori baik sebesar $52,1 \%$ (38 orang). Perilaku seksual remaja dalam masa pubertas tergolong baik sebesar $72,6 \%$ (53 orang). Terdapat hubungan rendah peran orang tua dengan perilaku seksual remaja SMA 1 Turi dengan nilai 0,201 dan $p=0,028(p<0,05)$. Terdapat hubungan sedang sumber informasi dengan perilaku seksual pada remaja SMAN 1 Turi serta dengan nilai 0,458 dan $p=0,000(p<0,05)$. Terdapat hubungan positif peran orang tua dan sumber informasi dengan perilaku seksual pada remaja SMAN 1 Turi didapatkan nilai $p=0,000(p<0,05)$. Saran bagi orang tua agar lebih meningkatkan pengetahuan tentang pendidikan kesehatan.

\section{RUJUKAN}

1. Badan Pusat Statistik. Hasil Sensus Penduduk [internet]. 2010 [cited 2013 November 30]. Available from: http://www.bps.go.id.

2. Badan Koordinasi Keluarga Berencana Nasional. 2009. Buku Penyuluhan Bina Keluarga Remaja [internet]. 2009 [cited 2013 Desember 10]. Available from: http:// www.bkkbn.go.id.

3. Dariyo A. Psikologi Perkembangan remaja. Bogor: Ghalia Indonesia; 2004.
4. Wong DL. Buku Ajar Keperawatan Pediatrik. Jakarta: EGC; 2008.

5. Nursal D. Faktor-Faktor yang Berhubungan dengan Perilaku Seksual Murid SMU Negri di Kota Padang Tahun 2007. Jurnal Kesehatan Masyarakat. 2008;2(1):175-180.

6. Departemen Kesehatan Republik Indonesia. Riset Kesehatan Dasar. Jakarta: Departemen Kesehatan Republik Indonesia; 2010.

7. Suprapti, Indrawati. Peran Orang Tua dan Pengetahuan Remaja tentang Pubertas di Salah Satu SMP Negeri Boyolali. GASTER. 2013;10(1):20-27.

8. Notoadmojo S. Promosi Kesehatan: Teori dan Aplikasinya. Jakarta: Rineka Cipta; 2005.

9. Soetjiningsih. Tumbuh Kembang Remaja dan Permasalahannya. Jakarta: CV. Sagung Seto; 2004.

10. Retno N. Upaya Menurunkan Perilaku Seks Bebas pada Remaja [internet]. 2012 [cited 2014 Juli 22]. Available from: http:// library. uksw. edu/ bistream/ TI_1320007016. judul. pdf/.

11. Darmasih. Faktor yang Mempengaruhi Perilaku Seks Pra Nikah pada Remaja SMA di Surakarta. Surakarta: Universitas Muhamadiyah Surakarta Fakultas Kesehatan Masyarakat; 2009.

12. Sarwono SW. Psikologi Remaja. Jakarta: Rajawali Pers; 2013.

13. Kurnia DS, Yulian T. Komunikasi Orang Tua dan Perilaku Seksual Remaja SMK di Baturaja. Jurnal Pembangunan Manusia. 2010;4(11):1-19.

14. Sujalmo P. Hubungan Peran Orang Tua terhadap Kenakalan Remaja di SMP 2 Mlati Sleman. Yogyakarta: FKU UGM Program Studi IImu Keperawatan Yogyakarta; 2009.

15. Panuju P, Ida U. Psikologi Remaja. Yogyakarta: Tiara Wacana; 2005.

16. Hidayana RS. Faktor-Faktor yang Berhubungan dengan Perilaku Seksual Beresiko pada Remaja SMAN 5 Takengon. Jurnal Kesehatan Masyarakat. 2013;1(1):1-10.

17. Indah AP. Pengaruh Layanan Informasi dengan Menggunakan Media Poster Terhadap Pencegahan Perilaku Seksual dalam Berpacaran Siswa Kelas VIII SMP Islam At-Ittihad. Semarang: Universitas IKIP PGRI Jurusan Psikologi Pendidikan dan Konseling; 2012. 